\title{
Features of drawing therapy in the correction of anxiety in primary school children
}

\author{
A.A. Kozhurova ${ }^{1 *}$, and A.N. Neustroeva ${ }^{2}$ \\ ${ }^{1}$ M.K. Ammosov North-Eastern Federal University, Yakutsk, Russia \\ ${ }^{2}$ M.K. Ammosov North-Eastern Federal University, Yakutsk, Russia
}

\begin{abstract}
The article deals with the study of the nature of anxiety and its impact on personal development, manifested in primary school children. The aim of the study is to identify the features of the influence of drawing therapy on the correction of anxiety in primary school children. The hypothesis of the study is presented as an assumption that the correction of anxiety in children of primary school age will be more successful if a set of classes is used by the method of drawing therapy in compliance with the following pedagogical conditions: classes include various forms of drawing therapy for the correction of anxiety in children, including in remote mode in the conditions of quarantine measures of the pandemic; in the course of classes, adapted individual work is carried out. A description of the entire study on the tasks set is given: to identify the initial levels of anxiety in children; implement an empirical study on the adapted correctional program of drawing therapy and verify the results by monitoring the diagnosis of anxiety in primary school children. The research work is carried out on the basis of school No. 20. Yakutsk, among the students of the 4 th grade in the number of 29 people.
\end{abstract}

\section{A problem statement}

Nowadays the anxiety is rather common phenomenon in our modern society. So the study of the emotional disorders and its correction in children remains very actual. Particular importance is given to the study of nature of general anxiety defined in younger students of primary school and its influence on their personal development, due to the fact that they enter a new social environment and master a new activity - study. And these disabilities in the future will determine the child interaction with the outside world, his or her social communications. That is why so important to correct this children anxiety in a timely manner.

The great interest of specialists and potential clients is caused by drawing therapy. Drawing therapy is a method associated with revealing the creative potential of an individual, releasing his hidden energy resources and, as a result, finding optimal ways to solve his own problems. Each person has his own private story. In this story there are both happy and sad moments, problems. There are also situations that each person really want to

\footnotetext{
* Corresponding author: prof-ped.gpa@mail.ru
} 
remember, relive, maybe rethink, but access to them is denied. Drawing therapy is a key for such situations.

Anxiety problems are studied by many foreign researchers (O. Maurer, R. May, J. Taylor) [1-5] and domestic scientists (V.M. Astapov, A.M. Prikhozhan, Yu.L. Khanin) [69]. In our country anxiety is studied in a narrow sense of certain problems: school anxiety (E.V. Novikova, V.S. Mukhina, A.M. Prikhozhan) [10, 11], anxiety of expectations in social communication (V.R. Kislovskaya, A.M. Prikhozhan) [10, 12].

A fairly large number of studies are devoted to the study of anxiety in adolescents and adults, and the amount of studies about correction of anxiety in younger schoolchildren is rather not enough. This suggests that children with anxiety are not provided with corresponding help. As a result, children have psychological problems that can contribute to the appearance of neurosis (A.I. Zakharov, A.S. Spivakovskaya) [13, 14]; negative changes in behavior occur, organization in all areas of activity disappears (N.V. Imedadze, Ch. Spilberg Ch. Spielberger, I.A. Musina) [15-19].

Insufficient analysis of anxiety in children of primary school age cannot clearly determine its impact on the development of child as a personality in the future. It is important to note that such studies can solve a number of problems in children of primary school age, as well as - problems during a crisis period, problems of adaptation in school, educational achievement and many other difficulties. This is necessary in order for the authors to touch on this topic more deeply and study different methods for correcting anxious children (O.B. Kulikovskaya, I.A. Levochkina, S. Levis, etc.).

Though, the researchers insist on the need to diagnose anxiety as a stable characteristic and propose to use the method of the family and pedagogical environments optimization (A.M. Prikhozhan) [9], using gaming therapy (A.I. Zakharov) [13] for its correction/ But, however, the corrective resources of drawing therapy are left without any suitable attention.

\subsection{The objective of the work}

Based on shown facts, the main purpose of the study is to identify the features of the of drawing therapy and its influence on the correction of younger schoolchildren's of anxiety. Object of study: anxiety of younger schoolchildren. The subject of the study: correcting the anxiety of younger schoolchildren through drawing therapy. The methodological basis of the study is made by the works of L.I. Bozhovich, N.D. Levitova, I.G. Krokhina, T.V. Dragunova, O.B. Frolova and others [20-24]. The correction program of W. Oaklander was also used [25].

\section{Results of the research}

The hypothesis of the study is the assumption that the correction of anxiety in children of primary school age will be more successful if a set of classes is used by the method of drawing therapy in compliance with the following pedagogical conditions: classes include various forms of drawing therapy for the correction of anxiety in primary school children, including in remote mode in the conditions of quarantine measures of the pandemic; in the course of classes, adapted individual work with children is conducted.

Based on the hypothesis, we identify the following research tasks:

1. Identify the initial levels of anxiety in primary school children.

2. Conduct an empirical study aimed at studying the effectiveness of classes through drawing therapy in children of primary school age.

3. Check the results of the study by re-diagnosing anxiety in order to assess the effectiveness of the correctional program. 
The research work was carried out on the basis of secondary school No. 20 in the city of Yakutsk, among students of the 4th grade in the number of 29 people. To create a calm and positive environment for the study, the children were given instructions in an accessible form and the meaning of the conversation was explained. The comprehensive study was conducted with the consent of the parents.

The work was carried out in three stages:

1. Ascertaining (diagnosis of anxiety in primary school children);

2. Formative (developing a program and conducting remedial classes aimed at reducing the anxiety of younger students);

3. Control (repeated diagnosis of anxiety in order to assess the effectiveness of the developed correctional program).

To diagnose anxiety by visual perception, we selected and used the following methods: the Phillips school anxiety test (B.N. Phillips); the projective method "Non-existent animal" (M.Z. Dukarevich); the method of unfinished sentences" (V.F. Petrenko, 1988).

School anxiety test (B.N. Phillips). This test examines the child's anxiety depending on various everyday situations in communicating with other people. An overestimated level of anxiety can be characterized as a poor emotional adaptability of the child to various situational episodes. This experiment examines the internal state of the child in certain situations, gives a positive or negative assessment of the child's relationship with peers and parents, at school.

As a result of the conducted methodology, we obtained the following indicators: out of 29 subjects, 15 students have a low level of anxiety, 10 students have an average level of anxiety, and 4 students have a high level (Fig. 1). By talking, we found out what factors affect anxiety in 4 subjects? Three students have a fear of a knowledge test situation and one student has a fear of not meeting the expectations of others. In a broader sense, fear means-the fear of earning blame, of doing something wrong, as it should be, as it is customary. Fear can also be the starting point of a younger student's anxiety (Figure 1).

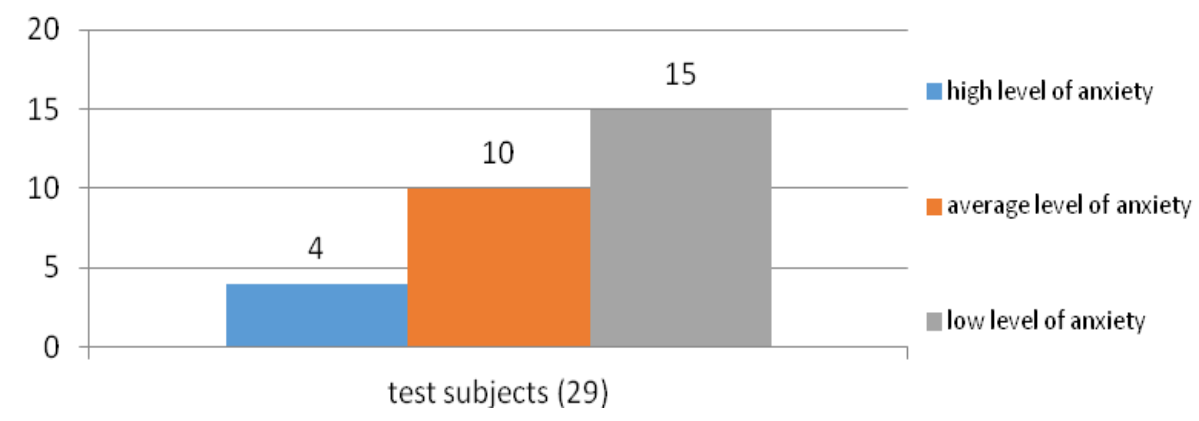

Fig. 1. Distribution of the results of anxiety levels according to the method of B.N. Phillips "Test of school anxiety" (pers.).

Next, we will consider the results of the method of M. Z. Dukarevich "Non-existent animal". As a result of the conducted methodology, the following indicators were obtained: out of 29 subjects, 17 students have a low level of anxiety, 8 students have an average level of anxiety, and 4 students have a high level of anxiety (Figure 2). 


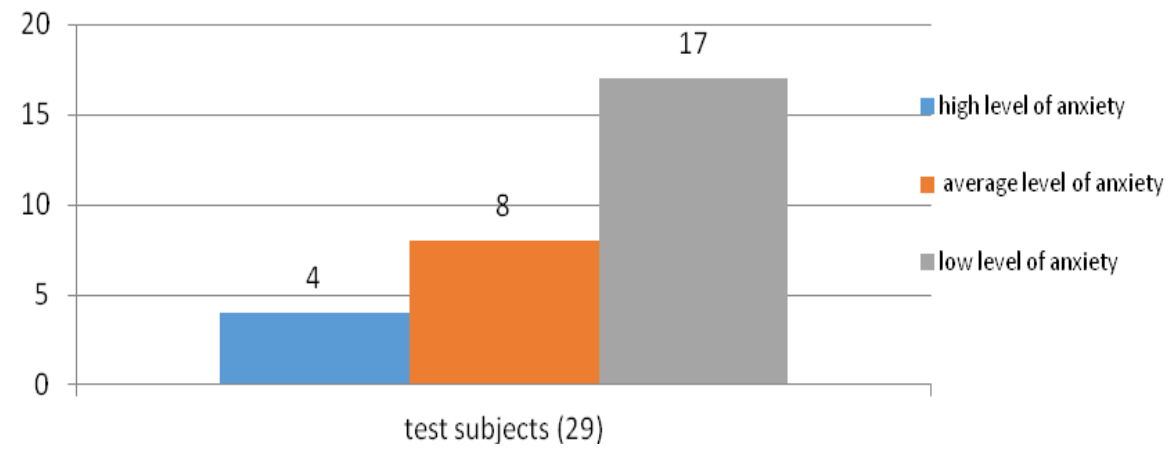

Fig. 2. Distribution of the results of anxiety levels according to the method of M.Z. Dukarevich "Nonexistent animal" (pers.).

Our last method conducted in the ascertaining stage is the" Method of unfinished sentences "by V. F. Petrenko, as a result of which the following results were obtained: "Favorable" answers - 24, "Unfavorable" answers-5 (Figure 3).

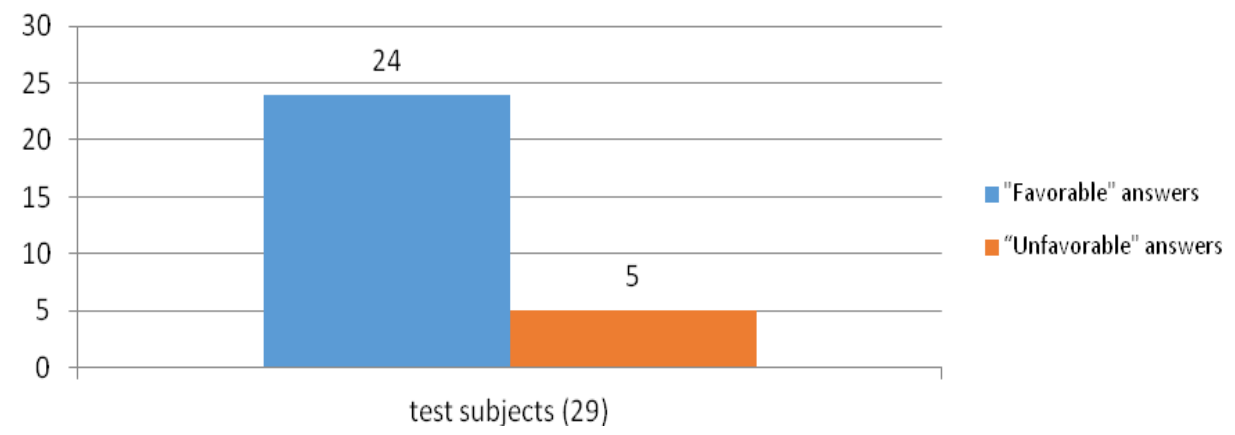

Fig. 3. Distribution of the results of the answers according to the method of V.F. Petrenko "The method of unfinished sentences".

Based on the indicators of Figure 3, we found out that the largest number of "unfavorable" answers in question № 2 "On the control...", that is, it is $48.2 \%$ of students. Most of the children responded with "I'm worried" and " I'm afraid." And the greatest number of "favorable" answers in question № 7 "When after the holidays I meet with classmates...", that is, it is $86.2 \%$ of students. This number of positive responses shows that the children are happy to see each other. Thus, from Figure 3, we can conclude that $82 \%$ of respondents have "Favorable "answers, and the remaining 18\% have "Unfavorable" answers. As experience shows, anxious children give 6 or more "dysfunctional" answers.

After the diagnostic measures were carried out, it was revealed that 4 students have anxiety. It is important to note that they showed positive responses to anxiety in all three methods, so a number of pedagogical conditions for correcting anxiety were implemented for these 4 subjects. Thus, after analyzing the results obtained during the ascertaining stage, we came to the conclusion that it is necessary to develop an adapted program to correct the anxiety of younger schoolchildren through drawing therapy (Table 1).

We chose thematic drawing as a means of correction based on the work of Marina V. Kiseleva, Associate Professor of the Department of Psychological Counseling at the St. Petersburg Institute of Psychology and Social Work, "Art Therapy in Working with Children: a guide for child psychologists, teachers, doctors and specialists working with children".

You can start the exercises in different ways. Some classes begin with an initial 
discussion, some spontaneously, and others by mutual agreement. Before each lesson, children are reminded that this is not a "drawing lesson", that there is no "right" or "wrong". They are told that there are many ways to express thoughts, feelings, and ideas: through various forms, colors, and textures; through object images; using symbols; using stick figures, ready-made pictures; combining all these methods (Table 1).

Table 1. Adapted correctional program developed by M.V. Kiseleva.

\begin{tabular}{|c|c|c|}
\hline Topic & Task & Content \\
\hline \multirow[t]{3}{*}{ 1. «I» } & "My card" - & $\begin{array}{l}\text { - a picture of various aspects of the personality (pleasant/evil } \\
\text { side, scared / brave...) }\end{array}$ \\
\hline & $\begin{array}{l}\text { "What I like about } \\
\text { myself" }\end{array}$ & $\begin{array}{l}\text { - a discussion of "what you like about yourself»" } \\
\text { - image in the form of movements of your own qualities and } \\
\text { behavior }\end{array}$ \\
\hline & $\begin{array}{l}\text { "My portrait in } \\
\text { the sun" }\end{array}$ & $\begin{array}{l}\text { - drawing a portrait, around it the rays of the sun, where the } \\
\text { personal qualities of the child are written }\end{array}$ \\
\hline \multirow[t]{3}{*}{$\begin{array}{l}\text { 2. "My } \\
\text { feelings" }\end{array}$} & "My mood" & $\begin{array}{l}\text { - an image of a mood or feeling using only shapes, lines, } \\
\text { colors, textures, tonality }\end{array}$ \\
\hline & $\begin{array}{l}\text { "Casket } \\
\text { Happiness" }\end{array}$ & (directed visualization) \\
\hline & $\begin{array}{l}\text { "Opposite } \\
\text { feelings" }\end{array}$ & $\begin{array}{l}\text { - draw two opposite feelings on one sheet of paper, on both } \\
\text { sides, or on two separate sheets. } \\
\text { "I like it when...", "I hate it when..." } \\
\text { "I had a good time when...", "I felt bad when..." }\end{array}$ \\
\hline \multirow[t]{2}{*}{$\begin{array}{l}\text { 3. "My } \\
\text { body" }\end{array}$} & $\begin{array}{l}\text { "What is said of } \\
\text { the newspaper" }\end{array}$ & $\begin{array}{l}\text { - from magazines-cut pictures, and of them are prepared image } \\
\text { (can be put together fragments of the parts or even rearrange } \\
\text { them). Images can be strange and unreal. They can be done } \\
\text { individually and all together }\end{array}$ \\
\hline & $\begin{array}{l}\text { "Map of } \text { My } \\
\text { Body" }\end{array}$ & $\begin{array}{l}\text { - explore fragmented or negative self-perception and start } \\
\text { moving towards a whole and more positive view } \\
\text { - "first card" - the image of the part of the body that you like } \\
\text { and the one that you don't like } \\
\text { - "second map" - connecting fragments } \\
\text { - comparison of the result }\end{array}$ \\
\hline \multirow[t]{3}{*}{$\begin{array}{l}\text { 4. "I and } \\
\text { society" }\end{array}$} & "Friendship" & $\begin{array}{l}\text { (directed visualization, imagination game) } \\
\text { - introduce yourself as a friend }\end{array}$ \\
\hline & $\begin{array}{l}\text { "Portraits of what } \\
\text { is inside/outside" }\end{array}$ & $\begin{array}{l}\text { - draw two portraits of yourself: one depicting you from the } \\
\text { outside, the other from the inside. } \\
\text { (You can use and combine any image styles) }\end{array}$ \\
\hline & "Overcoming" & $\begin{array}{l}\text { - in the first picture, the child represents a situation that causes } \\
\text { fear or anxiety } \\
\text { - in the second picture, the children depict how they overcome } \\
\text { this }\end{array}$ \\
\hline
\end{tabular}

Let's take a closer look at the exercises from the topic: "I", "My feelings", "My body", "I and society" (Table 1).

1) Exercise "My portrait in the sun". Purpose: to contribute to the deepening of the processes of self-disclosure, to teach to find the main individual characteristics, to determine their personal characteristics. Form of conduct: remote individual lesson. Material: a sheet of paper and a pen or pencils.

Exercise progress:

- Draw the sun, in the center of the sun circle, write your name or draw your portrait. Then, along the rays, write all your virtues, all the good things that you know about yourself. Try to have as many rays as possible. This will be the answer to the question: "Why do I deserve respect?».

2) Exercise "My mood". Goal: to develop an emotional state. Form of conduct: remote 
individual lesson. Material: a sheet of paper and colored pencils or watercolors.

Exercise progress:

- The child is asked to portray the mood or feelings using only shapes, lines, colors, textures, tonality, etc., but not using specific objects. You can ask the child to portray his mood now or how he felt in a particular situation. This exercise is best given after discussing how different colors and shapes can create different moods (for example, red can express excitement, anger, or energy; smooth shapes can seem calmer than sharp ones). However, it is important to remember that the perception of color or shape may differ from person to person.

3) Exercise "What the newspapers say". Goal: to identify a person's attitude to their physical appearance; to learn to listen and hear the inner "I"; to increase self-esteem. Form of conduct: remote individual lesson. Material: magazines, newspapers, glue, colored pencils, scissors, a sheet of paper.

Exercise progress:

- In newspapers, magazines, on television and in movies, we see images of people who are considered beautiful. We can only begin to think that we will become beautiful if we look like them. Let's take a fresh look at how we are made to look. Next, pictures are cut out of the magazines, and images of themselves are made up of them in parts. For example: a child can draw himself and glue the cut-out pieces of clothing from the magazine as he likes, can glue other objects that will decorate him next to it. That is, full freedom of choice is given, without restrictions. Images can be strange and unreal. They can be done individually and all together. The finished images are placed side by side, compared, and discussed "How do images affect us or our image? How do they affect our concept of what we should look like?".

4) Exercise "Overcoming". Goal: To help your child overcome their fears through visualization and drawing. Form of conduct: remote individual lesson. Material: sheet of paper, colored pencils.

Exercise progress:

- The child presents a situation that causes fear or anxiety (for example, speaking in front of the class, the need to prove their point of view). "Try to express the form and the feeling of fear in your drawing. What is he like? What does it look like? " In the second picture, the children depict how they overcome this (for example, performing in front of a large audience, telling someone about their feelings of anger or resentment). "Picture yourself doing what's bothering you. How do you feel about being able to do it? What does it look like?» You can save these drawings, refer to them, or use them as a basis for discussion.

Correctional classes were conducted individually with each student. There are two classes a week, each lasting no more than 30 minutes.

After the correction work, we conducted a conversation with the parents of the subjects. They noted that the children were looking forward to the next lesson, as they were very interested in drawing therapy. After all, in these classes, children open up and learn to overcome their fears.

The number of methods that make it easier for children to express their feelings when using drawing therapy is endless. Working with a child is a process that requires caution and delicacy, a process in which what is happening in the psychologist's soul interacts with what is happening in the child's soul. Visual art is a powerful means of self-expression, helping to realize self-identification and providing a way for the expression of feelings.

After carrying out the developed correctional program, a control diagnosis was carried out using the same methods as for detecting the level of anxiety in younger schoolchildren.

As a result of the two methods "B. N. Phillips School Anxiety Test" and "Nonexistent Animal", the following indicators of four subjects were obtained: 2 - high levels of anxiety 
and 2-medium levels (Figure 4).

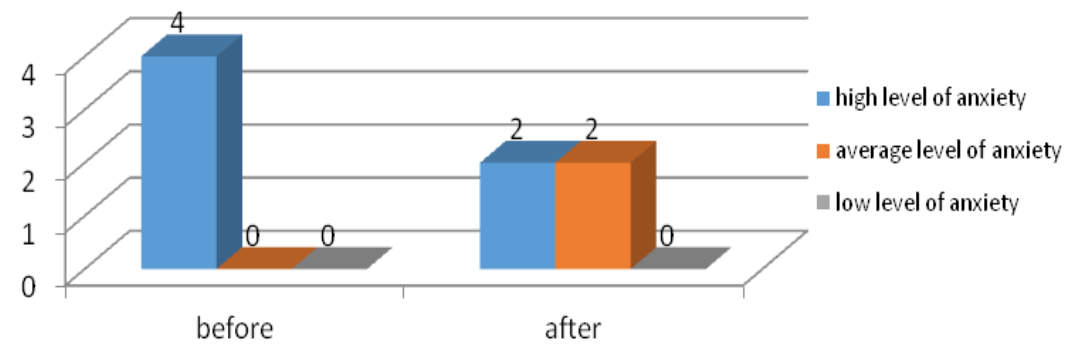

Fig. 4. Determination of the level of anxiety before and after the formative stage (pers.).

According to the method "Method of unfinished sentences" by V. F. Petrenko, the following results were obtained: "Favorable" answers-2, "Unfavorable" answers-2 (Figure 5).

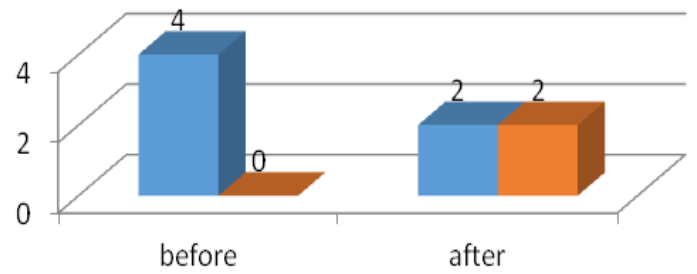

"Unfavorable" answers

"Favorable" answers

Fig. 5. Determining the level of anxiety from responses before and after the formative stage (pers.).

Thus, after the formative work in the control stage of the experiment, we received changes in the positive direction. And, as a result, we conducted a conversation with the parents of children who had a high level of anxiety: we learned that the children were looking forward to the next lesson, as they were very interested in drawing therapy. And also noted that the adapted correctional program is to help parents in leisure education in the family, these are useful and exciting activities. Therefore, our hypothesis that the use of drawing therapy will help to reduce the level of anxiety in primary school children, received its modest confirmation.

\section{Conclusions}

The results obtained in the course of this study allowed us to draw the following conclusions: the correction of anxiety in children of primary school age will be more successful if a set of classes is applied through drawing therapy; the main mission of drawing therapy is to harmonize the development of personality through the development of the ability of self-expression and self-knowledge.

The development of the correctional program was based on the methodological substantiation of methodological techniques for diagnosing and correcting mental activity in childhood: the work requires not a reduction or increase in the conditional level of the parameter, but the introduction of flexible and variable means, methods of "psychological tools" for regulating, mediating, and reproducing emotions and behavior into the arsenal of the child's individual experience. Such methods should become natural strategies for mediating direct emotional and behavioral responses: self-instruction, dividing activities into stages, rational assessment of opportunities in the activity, operating with cultural signs and means. In the future, we plan to review the program in more detail as it is used in practice with children who need a special educational approach. 


\section{References}

1. O.H. Mowrer, A stimulus-response analysis of anxiety and its role as a reinforcing agent, Psychol, 46(6), 553-565 (1939)

2. O.H. Mowrer, Learning theory and behavior (1950)

3. J. Dollard, L.W. Doob, N.E. Miller, O.H. Mowrer, R.R. Sears, Frustration and aggression (1939)

4. R. May, The meaning of anxiety (2001)

5. J.A. Taylor, A personality scale of manifest anxiety, Abnormal and Social psych, 48, 285-290 (1953)

6. V.M. Astapov, Functional approach to the study of the state of anxiety, Applied Psychology, 1, 41-47 (1999)

7. V.M. Astapov, Anxiety in children (2004)

8. Yu.L. Khanin, A brief guide to the use of the scale of personal and reactive anxiety (1976)

9. A.M. Prikhozhan, Psychological nature and age dynamics of anxiety (personal aspect) (1996)

10. A.M. Prikhozhan, Anxiety in children and adolescents: psychological nature and age dynamics (2000)

11. B.C. Mukhina, Developmental psychology: the phenomenology of development, childhood, adolescence (1998)

12. V.R. Kislovskaya, The relationship between sociometric status and symptom of anxiety of expectations in social interaction (1972)

13. A.I. Zakharov, How to help our children get rid of the fear (1995)

14. A.S. Spivakovskaya, Prevention of childhood neuroses: complex psychological correction (1988)

15. N.V. Imedadze, On the method of studying the level of anxiety (1971)

16. C.D. Spielberger, Theory and research on anxiety. Anxiety and behavior, 3-20 (1966)

17. C.D. Spielberger, Trait-state anxiety and motor behavior, Jour at Motor Beh, 3, 265$279(1971)$

18. C.D. Spielberger, The nature and measurement of anxiety, 3-12 (1976)

19. I.A. Musina, On the question of the optimum of anxiety (1988)

20. L.I. Bozhovich, Selected psychological works: Psychology of personality formation (1995)

21. N.D. Levitov, Mental state of anxiety, anxiety, Questions of psychology, 1, 131-138 (1969)

22. I.G. Krokhina, Investigation of the causes of anxiety of students, 1, 3 (2013)

23. T.V. Dragunova, The problem of conflict in adolescence, Voprosy psikhologii, 2, 2539 (1972)

24. O.B. Frolova, Psychological features of anxiety in frustrating situations and their psychological correction in children with mental retardation of primary school age (2001)

25. V. Oaklander, Windows to the world of the child. Guide to child psychotherapy (2003) 